\title{
Impacts of vigorous and non-vigorous activity on daily energy expenditure
}

\author{
Klaas R. Westerterp \\ Department of Human Biology, Maastricht University, PO Box 616, 6200 MD Maastricht, The Netherlands
}

\begin{abstract}
Activity intensity is a potential determinant of activity-induced energy expenditure. Tri-axial accelerometery is the most objective measurement technique for the assessment of activity intensity, in combination with doubly-labelled water for the measurement of energy expenditure under free-living conditions. Data on the effects of subject characteristics, including body size and age, and exercise training on the relationship between activity intensity and daily energy expenditure are reviewed. Average daily metabolic rate and non-basal energy expenditure are positively related to body size. The duration and intensity of physical activities do not need to be equivalent to the energy spent on activity. Obese subjects spend more energy on physical activity but can perform fewer activities, especially high-intensity (weight-bearing) activities, because of their higher body weight. Physical activity generally declines gradually from about 60 years of age onwards. Most subjects $>80$ years have an activity level well below the level defined for sedentary middle-aged adults. Spending relatively more time on low-intensity activities has a negative effect on the mean physical activity level. To obtain a higher physical activity level does not necessarily imply high-intensity activities. In an average subject $25 \%$ of the activity-induced energy expenditure may be attributed to high-intensity activities. Exercise training, as a form of highintensity activity, affects the physical activity level more in younger subjects than in elderly subjects.
\end{abstract}

Doubly-labelled water: Accelerometer: Obesity: Age: Exercise training

Average daily metabolic rate (ADMR) can be divided into three components: BMR; diet-induced energy expenditure; activity-induced energy expenditure (AEE). BMR covers the energetic costs of the processes essential for life. Diet-induced energy expenditure results from the digestion, absorption and conversion of food. AEE is the energy expenditure associated with muscular contractions involved in performing body postures and movements. Under most circumstances, the BMR of an individual accounts for the largest proportion of ADMR and is mainly determined by fat-free body mass. Diet-induced energy expenditure is about $10 \%$ of the ADMR in subjects consuming an average mixed diet that meets energy requirements. AEE is the most variable component of total energy expenditure. Depending on body size and physical fitness, a five- to twentyfold increase in metabolic rate can be sustained for a few minutes, while a healthy young adult can, if necessary, develop five to eight times the BMR over an $8 \mathrm{~h}$ working day (Bouchard et al. 1993).
In the general population physical activity level (PAL; ADMR/BMR) is between 1.2 and 2.2-2.5 (Westerterp, 1998). As a percentage of ADMR, AEE varies from 5 in a subject with a minimum PAL of $1 \cdot 2$ to $45-50$ in a subject with a PAL of $2 \cdot 2-2 \cdot 5$ (Fig. 1). At a PAL value of $1 \cdot 75$, about the average reported for the general population (Schulz \& Schoeller, 1994; Black et al. 1996; Westerterp, 1999a), AEE is one-third of daily energy expenditure. The present paper focuses on activity intensity as a determinant of the size of the AEE component of daily energy expenditure.

The doubly-labelled water method allows accurate measurement of ADMR in unrestricted conditions for periods of 1-3 weeks so that the relationship between activity intensity and daily energy expenditure can be assessed. This data is the basis for the present analysis, which will focus on three topics: (1) body size and physical activity; (2) AEE and age; (3) the effect of exercise on daily energy expenditure and its components. 


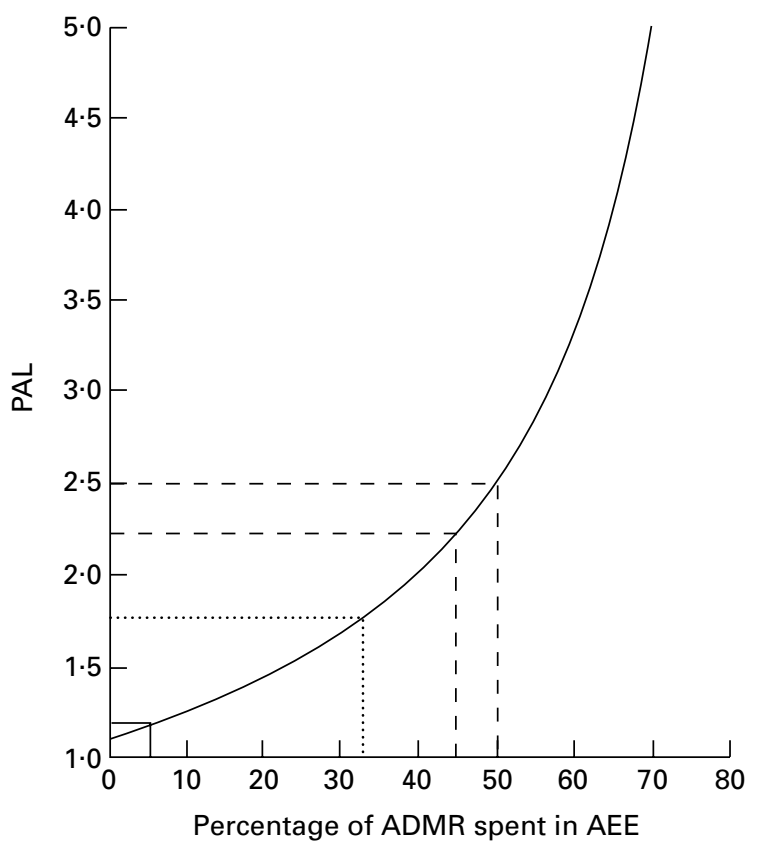

Fig. 1. Physical activity level (PAL), calculated as average daily metabolic rate (ADMR)/BMR, as a function of the percentage of ADMR spent in activity-associated energy expenditure (AEE). (-), Minimum PAL (1.2 and $5 \%$ ADMR as AEE); (.......), average PAL (1.75 and $33 \%$ ADMR as AEE); (-- ), maximum PAL (2.2-2.5 and 45-50\% ADMR as AEE).

\section{Methods}

Measurement of energy expenditure is done by direct or indirect calorimetry. For measurements over intervals of $\geq 1$ week under free-living conditions, the doubly-labelled water technique is the designated method. In this paper evaluation of the impact of vigorous and non-vigorous activity on daily energy expenditure is restricted to studies in which energy expenditure is measured under free-living conditions using doubly-labelled water.

Physical activity is generally measured using questionnaires, heart-rate monitoring and motion sensors. Motion sensors are the most objective technique for the assessment of physical activity, including activity intensity. So far, the tri-axial accelerometer has shown the best results for registering movement in validation studies using doublylabelled water as the standard method (Westerterp, 1999b). Unfortunately, there have not been many published studies that include physical activity assessment using tri-axial accelerometers.

For the present review additional evidence on the impact of vigorous and non-vigorous activity on daily energy expenditure was derived from intervention studies. Vigorous activity is often restricted or stimulated and relevant examples of restricted vigorous activity are studies in which subjects were observed under sedentary conditions in a respiration chamber and under free-living conditions using doubly-labelled water. Evidence for the effect of vigorous activity on energy expenditure was derived from studies using doubly-labelled water in which observations were conducted before and after participation in exercise training.
The impact of activity on daily energy expenditure can be evaluated from intervention studies, comparing data at different activity levels within the same subject, or by comparison between subjects. The latter requires correction of energy expenditure for differences in body size and body composition. There is no consensus on the way to normalise AEE for differences in body size. A frequently-used method for quantifying physical activity is to express ADMR as a multiple of BMR, PAL $=$ ADMR/BMR (World Health Organization, 1985). This approach assumes that the variation in ADMR is due to body size and physical activity. The effect of body size on ADMR is corrected for by expressing ADMR as a multiple of BMR. Carpenter et al. (1995) stated that the expression of ADMR as a multiple of BMR for comparison between subjects is precluded by the fact that the nature of the relationship between ADMR and BMR is highly variable between studies and often has a nonzero intercept. They proposed to adjust ADMR for BMR to correct for the effect of body size in a linear regression analysis. An alternative method used in many studies is to adjust AEE for differences in body size by expressing AEE per $\mathrm{kg}$ body mass, assuming that energy expenditure associated with physical activity is weight dependent (Schoeller \& Jefford, 2002).

\section{Results}

\section{Body size and physical activity}

Since the application of the doubly-labelled water method for the measurement of total energy expenditure in human subjects there have been three meta-analyses on the relationship between physical activity and obesity. Schoeller \& Fjeld (1991) had previously concluded that obese individuals expend slightly more energy in physical activity than non-obese individuals. Prentice et al. (1996a,b) suggested that, except in extreme obesity, patterns of physical activity are quite similar at different levels of BMI. In a later analysis it was confirmed that the majority of obese subjects are moderately active (Westerterp, 1999a). Ekelund et al. (2002) compared physical activity-associated energy expenditure as well as body movement in obese (BMI $>30 \mathrm{~kg} / \mathrm{m}^{2}$ ) and matched non-obese adolescents in whom physical activity was measured using doubly-labelled water, simultaneously with body movement measurements using an accelerometer. The obese subjects performed less body movement than the non-obese subjects even though there was no difference in PAL. The period of time $(\mathrm{min} / \mathrm{d})$ spent while sedentary and at physical activity of light intensity did not differ significantly between groups. Compared with the control group, the obese adolescents showed significantly $(P<0.05)$ less accumulated time at physical activity of moderate intensity, corresponding to walking at $4-6 \mathrm{~km} / \mathrm{h}$, and the total amount of body movement was significantly lower $(P<0.001)$ in the obese group.

In an intervention study subjects were trained to run a half-marathon competition after 44 weeks (Westerterp et al. 1992). The training consisted of four sessions per week, increasing running time from zero to $10-30 \mathrm{~min}, 20-60 \mathrm{~min}$ and 30-90 min per training session after 8, 20 and 40 weeks respectively. Nine of the thirty-two selected subjects (five 
of the sixteen women and four of the sixteen men) withdrew, being unable to keep up with the training programme. They all dropped out within 20 weeks of the start of the training. Reasons for giving up were "not enough time to join the training' ( $n$ 3), injuries ( $n$ 5) and not able to keep up with the training $(n 1)$. All dropouts had a BMI above the group mean of $23 \mathrm{~kg} / \mathrm{m}^{2}$ (Westerterp, 1999a). Although manifestly-obese subjects were excluded by the selection criteria, most subjects with a BMI $>24 \mathrm{~kg} / \mathrm{m}^{2}$ could not cope with the high-intensity exercise training.

In conclusion, ADMR and non-basal energy expenditure are positively related to body size. Duration and intensity of physical activities do not need to be equivalent to the energy spent on activity. Obese individuals spend more energy on physical activity but can perform fewer activities, especially high-intensity (weight-bearing) activities, because of a higher body weight.

\section{Activity-induced energy expenditure and age}

Physical activity declines with age. Black et al. (1996) concluded from an analysis of 574 doubly-labelled water measurements that the PAL for females is fairly constant between 13 and 64 years of age, and lower at younger and older ages. For males physical activity rises to a peak at 18-29 years of age and declines thereafter. Starling et al. (1998) reported a PAL of 1.68 (SD 0.28) in a group of about 100 subjects (69 (SD 8) years), with no significant difference between women and men. Westerterp \& Meijer (2001) reported a PAL of 1.76 (SD 0.20) in 20-34-year-old subjects, 1.79 (SD 0.25) for a group of 35-49-year-old subjects (no difference from that for 20-34-year-old subjects), 1.62 (SD 0.26) for a group of 60-74-year-old subjects (lower than that for 20-34-year-old subjects, $P<0 \cdot 001$ ), and 1.31 (SD 0.24) for $\geq 75$ years (lower than that for 20-34-year-old subjects, $P<0 \cdot 0001)$. There seems to be a gradual decline with age, starting at about age 60 years and getting more pronounced after age 80 years. A PAL of 1.67 denotes an AEE of $30 \%$ of the total energy expenditure (Fig. 1). Thus, on average, subjects of $\geq 65$ years spent $<30 \%$ of their daily energy expenditure on physical activity. Subjects of $>80$ years generally have an extremely low PAL, well below the level of 1.5 defined for sedentary adults (World Health Organization, 1985).

A few well-controlled studies have measured the effect of exercise intervention on PAL (Westerterp, 1998). Exercise intervention did increase the PAL, assessed using doublylabelled water, in four of five studies. The exception was a study involving 56-78-year-old subjects; the other four studies covered an age-range of 10-41 years. The authors suggested that the level of exercise was too vigorous, and thus fatigued the elderly participants for the remainder of the day, resulting in compensation for the training with a reduction in non-training activity (Goran \& Poehlman, 1992). Two later studies of elderly subjects confirmed that there is compensation of the training exercise, with a reduction in non-training activity, at a lower training load. Morio et al. (1998) trained 62.3 (SD 2.3)-year-old subjects and measured non-training activity using $7 \mathrm{~d}$ activity records. The PAL remained constant throughout the training period as a result of a compensatory decrease in non-training activity, even though the intensity was lower than that adopted by Goran \& Poehlman (1992). Meijer et al. (1999) observed compensation of moderate-intensity exercise training by a decrease in non-training physical activity in 59 (SD 4)-year-old subjects using a tri-axial accelerometer to register movement. It is intriguing to observe that the PAL of younger subjects was modified with exercise training, while exercise training had no effect in older subjects. To date, well-controlled training studies have been limited to younger subjects in the age range 10-41 years and to subjects $>55$ years.

Elderly subjects spent substantially more time on lowintensity activities than young adults (Meijer et al. 2001), where low-intensity activities are defined as $<3$ metabolic equivalents (work metabolic rate/BMR), representing lying, sitting and standing. In the elderly PAL is inversely related to the percentage time spent on low-intensity activities. No significant relationship was observed between PAL and the percentage of time spent on high-intensity activities.

In conclusion, physical activity generally declines gradually from about age 60 years onwards. Most subjects $>80$ years have a PAL well below the level defined for sedentary middle-aged adults. Spending relatively more time on low-intensity activities has a negative effect on the mean PAL. Achieving a higher PAL does not necessarily imply high-intensity activities.

\section{The effect of exercise on daily energy expenditure and its components}

The AEE of a subject with an average PAL of 1.75 is onethird of the ADMR (Fig. 1). The question is how AEE as a proportion of ADMR is a function of vigorous activity. Data are reviewed for AEE as measured under sedentary conditions in a respiration chamber, AEE as a function of the proportion of time spent in low-, moderate- and high-intensity activities in daily life and changes in AEE as a function of exercise training.

During a stay in a respiration chamber without an exercise protocol, physical activity is limited to low-intensity activities such as lying, sitting and standing, and moderateintensity activities such as walking. Thus, AEE reaches a minimum value for activities of daily living. Table 1 shows data from studies in which sleeping metabolic rate and $24 \mathrm{~h}$ energy expenditure were measured in a respiration chamber without an exercise protocol and ADMR was measured in the same subjects under free-living conditions using doublylabelled water. AEE can be calculated as daily energy expenditure minus $10 \%$ for diet-induced energy expenditure and minus sleeping metabolic rate. Thus, AEE for four studies (Westerterp et al. 1991; Schulz et al. 1992; Verboeket-van de Venne et al. 1993; Snitker et al. 2001) was respectively $17,19,19$ and $19 \%$ of the daily energy expenditure in a respiration chamber and 23, 35, 35 and $32 \%$ of the daily energy expenditure in daily life. Mean AEE, expressed as a proportion of daily energy expenditure in the restricted environment of a respiration chamber, was very similar for all four studies with very different subjects. Subjects in the study of Westerterp et al. (1991) were morbidly-obese Caucasians with a BMI of $>40 \mathrm{~kg} / \mathrm{m}^{2}$. The subjects in the studies of Schulz et al. (1992) and Verboeket- 
van de Venne et al. (1993) were normal-weight Caucasians and those in the study of Snitker et al. (2001) were normalweight Pima Indians. In normal-weight subjects (Schulz et al. 1992; Verboeket-van de Venne et al. 1993; Snitker et al. 2001) the mean AEE in daily life was nearly twice as high as that determined in a respiration chamber. In the morbidly-obese subjects (Westerterp et al. 1991) mean AEE in daily life was about $50 \%$ higher than that determined in a respiration chamber. The AEE of the normal-weight subjects was approximately one-third of the ADMR for a subject with a PAL of $1 \cdot 75$. The morbidly-obese subjects were very sedentary in daily life, with a mean PAL of 1.52 . It can be speculated from these results that at least $50 \%$ of the AEE in free-living conditions is associated with lowand moderate-intensity activities. On average, $\leq 25 \%$ of the AEE may be attributed to high-intensity activities. In daily life the activities additional to the activity pattern associated with a respiration chamber will include replacement of low-intensity activity with moderate- and high-intensity activities. The morbidly-obese subjects, with a limitation for the performance of high-intensity activities, predominantly replace low-intensity activities with moderateintensity activities, resulting in the $50 \%$ increase in AEE mentioned earlier. The normal-weight subjects showed a twofold increase in AEE.

Observations of the activity pattern with motion sensors combined with determination of PAL values using doublylabelled water can be used to obtain a more direct estimate of the contribution of high-intensity activity to ADMR. It was shown recently that subjects with a PAL ranging from 1.51 to 2.04 spend on average $9 \%$ of their active time in high-intensity activity (Westerterp, 2001a). In a multiple regression analysis of the proportion of time spent at activities of moderate and high intensity, only moderateintensity activity was a predictor of PAL. The data clearly showed that in the normal PAL range the distribution of time spent at activities of low and moderate intensity determines the activity level. High activity does not have much impact as a determinant of PAL in the normal population. An average subject with a PAL of 1.75 spends 65,25 and $9 \%$ of their active time in low-, moderate- and highintensity activity respectively. When energy costs for low:moderate:high intensity are 1:2:4, the contribution of high-intensity activity to AEE is about $25 \%$.

Exercise training is a form of high-intensity activity. Six studies (Bingham et al. 1989; Blaak et al. 1992; Goran \&

Table 1. Data from four studies in which sleeping metabolic rate (SMR) and $24 \mathrm{~h}$ energy expenditure (24hEE) were measured in a respiration chamber and average daily metabolic rate (ADMR) in daily life determined using doubly-labelled water

(Values are means and standard deviations)

\begin{tabular}{|c|c|c|c|c|c|c|c|c|c|c|c|c|}
\hline \multirow[b]{2}{*}{ Study } & \multicolumn{2}{|c|}{ No. of subjects } & \multicolumn{2}{|c|}{ Age (years) } & \multicolumn{2}{|c|}{ BMI $\left(\mathrm{kg} / \mathrm{m}^{2}\right)$} & \multicolumn{2}{|c|}{$\operatorname{SMR}(M J / d)$} & \multicolumn{2}{|c|}{ 24hEE (MJ/d) } & \multicolumn{2}{|c|}{$\operatorname{ADMR}(\mathrm{MJ} / \mathrm{d})$} \\
\hline & $\mathrm{F}$ & M & Mean & SD & Mean & SD & Mean & SD & Mean & $\mathrm{SD}$ & Mean & SD \\
\hline $\begin{array}{l}\text { Westerterp et al. } \\
\text { (1991) }\end{array}$ & 1 & 4 & 29 & 8 & $48 \cdot 7$ & $7 \cdot 9$ & $11 \cdot 3$ & $2 \cdot 0$ & $15 \cdot 5$ & $2 \cdot 8$ & $16 \cdot 9$ & $2 \cdot 9$ \\
\hline Schulz et al. (1992) & 9 & 0 & 26 & 3 & $19 \cdot 7$ & 0.8 & $5 \cdot 6$ & 0.3 & $7 \cdot 0$ & 0.4 & $11 \cdot 8$ & $1 \cdot 3$ \\
\hline $\begin{array}{l}\text { Verboeket-van de } \\
\text { Venne et al. (1993) }\end{array}$ & 0 & 10 & 43 & 12 & $24 \cdot 9$ & 3.6 & $6 \cdot 7$ & 0.4 & $9 \cdot 4$ & 0.8 & $12 \cdot 1$ & 0.9 \\
\hline Snitker et al. (2001) & 20 & 30 & 30 & 6 & - & - & $6 \cdot 8$ & $1 \cdot 1$ & $9 \cdot 6$ & $1 \cdot 6$ & $11 \cdot 8$ & $2 \cdot 2$ \\
\hline
\end{tabular}

F, Females; M, males.

Table 2. Data from six studies in which the physical activity level (PAL; average daily metabolic rate (ADMR)/resting metabolic rate) was measured before $\left(P A L_{\text {before}}\right)$ and at the end $\left(P A L_{\text {end }}\right)$ of a training programme, together with the change in $A D M R$ over the same period ( $\left.\triangle A D M R\right)$

\begin{tabular}{|c|c|c|c|c|c|c|c|c|c|c|c|}
\hline Study & Training programme & \multicolumn{2}{|c|}{ No. of subjects } & \multicolumn{2}{|c|}{ Age (years) } & \multicolumn{2}{|c|}{ PAL before } & \multicolumn{2}{|c|}{$P A L_{\text {end }}$} & \multicolumn{2}{|c|}{$\Delta$ ADMR (\%) } \\
\hline $\begin{array}{l}\text { Bingham et al. } \\
\text { (1989) }\end{array}$ & $\begin{array}{l}9 \text { weeks of jogging for } \\
\leq 1 \mathrm{~h} / \mathrm{d}\end{array}$ & 2 & 3 & 30 & 3 & $1 \cdot 58$ & $0 \cdot 11$ & 1.99 & 0.31 & 27 & 17 \\
\hline Blaak et al. (1992) & $\begin{array}{l}4 \text { weeks of cycling five } \\
\text { times for } 1 \mathrm{~h} / \mathrm{d}\end{array}$ & 0 & 10 & 11 & 1 & $1 \cdot 77$ & $0 \cdot 15$ & $2 \cdot 04$ & $0 \cdot 15$ & 12 & 6 \\
\hline $\begin{array}{l}\text { Goran \& Poehlman } \\
\quad(1992)\end{array}$ & $\begin{array}{l}8 \text { weeks of cycling } \\
\text { three sessions per } \\
\text { week }\end{array}$ & 5 & 6 & 66 & 6 & 1.51 & - & $1 \cdot 40$ & - & 3 & - \\
\hline $\begin{array}{l}\text { Westerterp et al. } \\
\text { (1992) }\end{array}$ & $\begin{array}{l}40 \text { weeks of jogging } \\
\text { for up to } \\
50 \mathrm{~km} / \text { week }\end{array}$ & 5 & 8 & 37 & 3 & $1 \cdot 68$ & $0 \cdot 18$ & $2 \cdot 08$ & $0 \cdot 17$ & 21 & 9 \\
\hline $\begin{array}{l}\text { Van Etten et al. } \\
\text { (1997) }\end{array}$ & $\begin{array}{l}18 \text { weeks of weight } \\
\text { training for } 2 \mathrm{~h} / \text { week }\end{array}$ & 0 & 12 & 33 & 6 & $1 \cdot 76$ & $0 \cdot 14$ & $1 \cdot 92$ & $0 \cdot 18$ & 9 & 8 \\
\hline Hunter et al. (2000) & $\begin{array}{l}26 \text { weeks of } \\
\text { resistance training } \\
\text { for } 2.3 \mathrm{~h} / \text { week }\end{array}$ & 7 & 8 & 67 & 4 & $1 \cdot 45$ & - & 1.53 & - & 12 & 15 \\
\hline
\end{tabular}

$\mathrm{F}$, females; M, males. 
Poehlman, 1992; Westerterp et al. 1992; Van Etten et al. 1997; Hunter et al. 2000) measured the effect of exercise training on ADMR, with observations made before and at the end of the training period (Table 2). PAL before the start of the training was in the normal range, with lower values for the elderly subjects (Goran \& Poehlman, 1992; Hunter et al. 2000) than for the younger subjects (Bingham et al. 1989; Blaak et al. 1992; Westerterp et al. 1992; Van Etten et al. 1997). The effect of an increase in high-intensity activity on PAL was more pronounced in the younger subjects even though the PAL value was higher at baseline. The effect of exercise training on ADMR can be the result of a change in BMR and in AEE. In sedentary subjects exercise training does not influence BMR when body weight is maintained, and the exercise-induced change in AEE is about twice the training load (Westerterp, 1998). There is an increase in the efficiency, i.e. a decrease in energy expenditure at the same training load, as a result of training. In elderly subjects undergoing an exercise training programme results in an increase in physical activity that is compensated by a decrease in nontraining physical activity (Meijer et al. 1999).

In conclusion, in an average subject with a PAL of 1.75 , $25 \%$ of the AEE may be attributed to high-intensity activities. The distribution of time spent at activities with low and moderate intensity determines PAL. Exercise training, as a form of high-intensity activity, affects PAL more in younger subjects than in elderly subjects.

\section{Discussion}

The studies reviewed included data on activity and energy expenditure in 'normal' healthy subjects, excluding studies in endurance athletes and studies in which energy intake is restricted. In the general population PAL ranges from 1.2 to $2 \cdot 2-2 \cdot 5$. The upper limit of sustainable metabolic rate is about twice as high in endurance athletes, mainly because of long-term exercise training with simultaneous consumption of food supplements during exercise. Endurance athletes have an increased fat-free mass and can maintain energy balance at a PAL value of 4.0-5.0 (Westerterp, 2001b). Thus, up to $70 \%$ of daily energy expenditure is spent in AEE (Fig. 1). Normally, subjects spend on average $1.5 \mathrm{~h} / \mathrm{d}$ at activities of high intensity (Westerterp, 2001a), whereas endurance athletes with PAL values of $4 \cdot 0-5 \cdot 0$, such as in the Tour de France, spend at least $6 \mathrm{~h} / \mathrm{d}$ (Westerterp et al. 1986).

There are indications that activity, especially highintensity activity, is limited at a negative energy balance. The addition of exercise to an energy-restricted diet results in little further weight loss. Exercise does not reverse the weight loss-induced reduction in resting metabolic rate, and weight loss is not different for groups undergoing dietary restriction and dietary restriction plus exercise. The latter finding suggests that the direct cost of the exercise training is compensated by a reduction in AEE outside the training sessions. Two studies compared AEE before and after dietary restriction and dietary restriction plus exercise, as measured using doubly-labelled water. Racette et al. (1995) designed diets to promote a weight loss of $1 \mathrm{~kg} /$ week by prescribing a diet in the diet-only group while adding the calculated energy costs of the exercise for the diet plus exercise group to create a comparable energy deficit. They observed that in the exercise group ADMR was maintained, while in the diet-only group ADMR decreased. Kempen et al. (1995) provided all subjects with an identical lowenergy formula diet. They observed a comparable decrease in ADMR in the diet-plus-exercise and the diet-only group. ADMR dropped markedly, and to a similar extent, with both treatments, suggesting no net effect of the exercise training on AEE. Explanations for the relatively minor or non-existent effect of adding exercise training to an energyrestricted diet treatment are a low compliance to the exercise prescription and/or a negative effect of exercise training on dietary compliance. The overall conclusion was that the extent of the exercise intervention had only a minor, or no, effect on the activity level of the subjects, and consequently did not result in additional weight loss. Furthermore, there are studies showing the effect of energy restriction per se on physical activity. Velthuis-te Wierik et al. (1995) observed the effect of a moderately-energy-restricted diet on energy metabolism in non-obese men (BMI 24.9 (SD 1.9) kg/m²). For 10 weeks subjects received a diet adjusted to $67 \%$ of their measured ADMR during weight maintenance. The consequent weight loss was 7.4 (SD 1.7) $\mathrm{kg}$ and the PAL (ADMR/BMR) decreased from 1.85 (SD 0.37) to 1.65 (SD $0.29 ; P=0.06$ ), i.e. there was a tendency for a reduction in physical activity when energy intake was reduced. In the long term a negative energy balance causes a decrease in physical activity, as observed in anorexic women (Bouten et al. 1996). Subjects with low BMI had lower levels of daily physical activity. They spent less time than subjects with a higher BMI on high-intensity activities such as sports and exercise and more time on low-intensity activities such as standing, lying, or sitting. Thus, in subjects with a lower BMI physical activity decreases as a consequence of malnutrition and declining physical capacity.

\section{References}

Bingham SA, Goldberg GR, Coward WA, Prentice AM \& Cummings JH (1989) The effect of exercise and improved physical fitness on basal metabolic rate. British Journal of Nutrition 61, 155-173.

Blaak EE, Westerterp KR, Bar-Or O, Wouters LJM \& Saris WHM (1992) Efffect of training on total energy expenditure and spontaneous activity in obese boys. American Journal of Clinical Nutrition 55, 777-782.

Black AE, Coward WA, Cole TJ \& Prentice AM (1996) Human energy expenditure in affluent societies: an analysis of 574 doubly-labelled water measurements. European Journal of Clinical Nutrition 50, 72-92.

Bouchard C, Shephard RJ \& Stephens T (1993) Physical Activity, Fitness, and Health, Consensus Statement. Champaign, IL: Human Kinetics Publishers.

Bouten CVC, Van Marken Lichtenbelt WD \& Westerterp KR (1996) Influence of body mass index on daily physical activity in anorexia nervosa. Medicine and Science in Sports and Exercise 28, 967-973.

Carpenter WH, Poehlman ET, O’Connell M \& Goran MI (1995) Influence of body composition and resting metabolic rate on variation in total energy expenditure: a meta-analysis. American Journal of Clinical Nutrition 61, 4-10. 
Ekelund U, Aman J, Yngve A, Renman C, Westerterp K \& Sjöström M (2002) Physical activity but not energy expenditure is reduced in obese adolescents: a case-control study. American Journal of Clinical Nutrition 76, 935-941.

Goran MI \& Poehlman ET (1992) Endurance training does not enhance total energy expenditure in healthy elderly persons. American Journal of Physiology 263, E950-E957.

Hunter GR, Wetzstein CJ, Fields DA, Brown A \& Bamman MM (2000) Resistance training increases total energy expenditure and free-living physical activity in older adults. Journal of Applied Physiology 89, 977-984.

Kempen KPG, Saris WHM \& Westerterp KR (1995) Energy balance during 8 weeks energy-restrictive diet with and without exercise in obese females. American Journal of Clinical Nutrition 62, 722-729.

Meijer EP, Goris AHC, Wouters L \& Westerterp KR (2001) Physical inactivity as a determinant of the physical activity level in the elderly. International Journal of Obesity 25, 935-939.

Meijer EP, Westerterp KR \& Verstappen FTJ (1999) The effect of exercise training on total daily physical activity in the elderly. European Journal of Applied Physiology 80, 16-21.

Morio B, Montaurier C, Pickering G, Ritz P, Fellmann N, Coudert J, Beaufrère B \& Vermorel M (1998) Effects of 14 weeks of progressive endurance training on energy expenditure in elderly people. British Journal of Nutrition 80, 511-519.

Prentice AM, Black AE, Coward WA \& Cole TJ (1996a) Energy expenditure in overweight and obese adults in affluent societies: an analysis of 319 doubly-labelled water measurements. International Journal of Obesity 50, 93-97.

Prentice AM, Goldberg GR, Murgatroyd PR \& Cole TJ (1996b) Physical activity and obesity: problems in correcting energy expenditure for body size. International Journal of Obesity $\mathbf{2 0}$, 688-691.

Racette SB, Schoeller DA, Kushner RF, Neil KM \& HerlingIaffaldano K (1995) Effects of aerobic exercise and dietary carbohydrate on energy expenditure and body composition during weight reduction in obese women. American Journal of Clinical Nutrition 61, 486-494.

Schoeller DA \& Fjeld CR (1991) Human energy metabolism: what have we learned from the doubly labeled water method? Annual Reviews of Nutrition 11, 355-373.

Schoeller DA \& Jefford G (2002) Determinants of the energy costs of light activities: inferences for interpreting doubly labeled water data. International Journal of Obesity 26, 97-101.

Schulz LO, Alger S, Harper I, Wilmore JH \& Ravussin E (1992) Energy expenditure of elite female runners measured by respiratory chamber and doubly labeled water. Journal of Applied Physiology 72, 23-28.
Schulz LO \& Schoeller DA (1994) A compilation of total daily energy expenditures and body weights in healthy adults. American Journal of Clinical Nutrition 60, 676-681.

Snitker S, Tatarranni PA \& Ravussin E (2001) Spontaneous physical activity in a respiratory chamber is correlated to habitual physical activity. International Journal of Obesity 25, 1481-1486.

Starling RD, Toth MJ, Carpenter WH, Matthews DE \& Poehlman ET (1998) Energy requirements and physical activity in freeliving older women and men: a doubly labeled water study. Journal of Applied Physiology 85, 1063-1069.

Van Etten LMLA, Westerterp KR, Verstappen FTJ, Boon BJB \& Saris WHM (1997) Effect of an 18-wk weight-training program on energy expenditure and physical activity. Journal of Applied Physiology 82, 298-304.

Velthuis-te Wierik EJM, Westerterp KR \& Van den Berg H (1995) Impact of a moderately energy-restricted diet on energy metabolism and body composition in non-obese men. International Journal of Obesity 19, 318-324.

Verboeket-van de Venne WPHG, Westerterp KR \& Kester ADM (1993) Effect of the pattern of food intake on human energy metabolism. British Journal of Nutrition 70, 103-115.

Westerterp KR (1998) Alterations in energy balance with exercise. American Journal of Clinical Nutrition 68, 970S-974S.

Westerterp KR (1999a) Obesity and physical activity. International Journal of Obesity 23, Suppl. 1, 59-64.

Westerterp KR (1999b) Assessment of physical activity level and energy expenditure of activity: current evidence and research issues. Medicine and Science in Sports and Exercise 31, S522-S525.

Westerterp KR (2001a) Pattern and intensity of physical activity. Nature 410, 539.

Westerterp KR (2001b) Limits to sustainable human metabolic rate. Journal of Experimental Biology 204, 3183-3187.

Westerterp KR \& Meijer EP (2001) Changes in physical activity patterns with age: a physiological perspective. Journal of Gerontology 56A, 7-12.

Westerterp KR, Meijer GAL, Janssen EME, Saris WHM \& Ten Hoor F (1992) Long-term effect of physical activity on energy balance and body composition. British Journal of Nutrition $\mathbf{6 8}$, 21-30.

Westerterp KR, Saris WHM, Soeters PB \& Ten Hoor F (1991) Determinants of weight loss after vertical banded gastroplasty. International Journal of Obesity 15, 529-534.

Westerterp KR, Saris WHM, Van Es M \& Ten Hoor F (1986) Use of the doubly labeled water technique in humans during heavy sustained exercise. Journal of Applied Physiology 61, 2162-2167.

World Health Organization (1985) Energy and Protein Requirements. Report of a Joint FAO/WHO/UNU Expert Consultation. Technical Report Series no. 724. Geneva: WHO. 